AUDIT

\title{
AUDIT TO EVALUATE THE PATIENTS VIEW, REGARDING THE PRE OPERATIVE VISIT OF THE PATIENTS BY THE ANAESTHETIST
}

\author{
T C M G P G Cooray \\ Acting consultant in Anaesthesiology, Base Hospital, Avissawella. \\ *Corresponding Author: prashanth.cooray@gmail.com
}

Key words: preoperative, procedure

\begin{abstract}
Preoperative anaesthetistic visit is an essential component in the present day management of anaesthesia. This not only allows the anaesthetic risk assessment of the patient but also gives an opportunity to optimise the patient. We seldom consider the patient's views on this visit by the anaesthetist. The aim of this audit was to get an understanding of the patients outlook towards these visits. The audit was carried out in three hundred patients using a questionnaire $86.6 \%$ responded. $90 \%$ of them had benefited from the preoperative visit by the anaesthetist. Only $16.5 \%$ were satisfied with the time the anaesthetist spent with them. This was mainly with the patients under going major surgery. Only $27.3 \%$ patients were satisfied with the explanation of the anaesthetic procedure. $5 \%$ of the patients were not satisfied with the opportunity given for them to express their views. $6.5 \%$ of the patients became more anxious after the anaesthetist's visit.
\end{abstract}

Pre operative Anaesthetic visit of the patient, plays a pivotal role in preparing the patient's physiology and psychology for anaesthetic and surgical procedures. This enables them to meet their Anaesthetist, learn about the anaesthetic procedure that they are undergoing and discuss their views. This is a basic fundamental right of every surgical patient. This exercise is bidirectionally beneficial to the patient as well as to the anaesthetist to meet the challenges of anaesthetic procedures more confidently. This encounter enables the anaesthetist to prepare his patient optimally in physiological and medical aspects and also to prepare his psychology to accept the anxiety and stress associated with anaesthesia and surgery.

In Avissawella base hospital, where we conducted our audit, anaesthetists routinely go and meet surgical patients in the ward on the day before the surgery. During this visit, they interview the patient and sometimes even their bystanders, namely patient's sons and daughters. This gives the anaesthetist a good opportunity to get a very detailed history regarding the medical conditions of the patient, current medications, base line exercise tolerance, any anaesthetic exposure in the past and allergic history. After taking a proper history and going through the medical records and investigations, they examine the patient and document their findings in the patient's notes. Furthermore, if they find any significant clinical abnormality or abnormal investigations, they discuss them with their consultant anaesthetist. This allows them to do the fine tuning in optimizing their patient maximally and do further investigations if needed.

According to the publication on "pre op assessment and the role of the anaesthetist " by the Association of anaesthetists of Great Britain and Ireland, the anaesthetists pre operative visit to the patient creates confidence and trust towards anaesthetist and anaesthetic procedures. Patients feel reassured that the anaesthetist sees him as a person to be protected from harm as well as giving technically safe care. This dialogue also brings in discussion of risks and benefits. This is the time for the patient to raise any doubts and questions about all aspects of anaesthetic care. Finally, this is the time for getting the patient's explicit consent 
to what is agreed. Therefore, well planned, proper pre operative anaesthetistic visit, gives a significant amount of benefits to the patient in understanding and preparing for anaesthesia.

\section{Materials and Methods}

Audit was conducted in the Base Hospital, Avissawella which is a regional hospital in one border of the Western province. There are direct admissions of patients and referrals from smaller hospitals of Ratnapura and Kegalle districts which result in a high patient turn over. Patients were selected from all surgical wards, namely general surgical, gynaecology and obstetrics, ENT, Eye and maxillo facial wards.

Three hundred patients were selected from all the above mentioned surgical facilities over a one month period. Patients were considered eligible at and above sixteen years. This was defined as patients able to read, understand and respond rationally to the questionnaire, which they were handed over by the ward staff. Both males and female patients were included in the study. After carefully selecting the patients, they were given the simple questionnaire soon after the anaesthetists visit and before coming to the operation theatre. Adequate number of nurses were given instructions to carry out the distribution and collection of questionnaires. They were given instructions to help patients whenever they found difficulty in understanding or filling the form, without influencing the patient's opinion. Data sheets were collected once in every three days. The anaesthetist involved in the pre operative visit did not collect the data sheets. This was to avoid bias or over reaction towards the study from the involved parties. We also tried our best to preserve patient's privacy and anonymity as far as possible.

\section{Results}

Out of three hundred patients only two hundred and sixty patients filled the questionnaire correctly and handed over to the nursing staff. According to the collected data most of the patients came from general surgical wards followed by gynaecology and obstetrics ward. There was only minor contribution from ENT, Eye and Maxillo facial wards
If we consider the age distribution majority of our patients represented the middle age group (nearly 60\%). One reason for this is that we distributed our questionnaire to patients warded for elective surgery, did not consider casualties and emergencies and defined a lower limit to the age group, as sixteen.

Age distribution of the study population
\begin{tabular}{|l|l|l|l|l|}
\hline Age & Frequency & $\%$ & Valid $\%$ & $\begin{array}{l}\text { Cumulative } \\
\%\end{array}$ \\
\hline $16-25$ years & 31 & 11.9 & 11.9 & 11.9 \\
\hline $26-35$ years & 47 & 18.1 & 18.1 & 30.0 \\
\hline $36-45$ years & 63 & 24.2 & 24.2 & 54.2 \\
\hline $\mathbf{4 6 - 5 5}$ years & $\mathbf{8 2}$ & 31.5 & $\mathbf{3 1 . 5}$ & $\mathbf{8 5 . 8}$ \\
\hline$>55$ years & 37 & 14.2 & 14.2 & \\
\hline Total & 260 & 100.0 & 100.0 & 100.0 \\
\hline
\end{tabular}

When we take the hospital statistics, there is a higher number of minor surgeries when compared to that of major category. But in our study population that difference was not very significant.

\section{Type of surgery}

\begin{tabular}{|l|l|l|l|l|}
\hline & Frequency & $\%$ & Valid \% & Cumulative \% \\
\hline $\begin{array}{l}\text { minor } \\
\text { surgery }\end{array}$ & 139 & 53.5 & 53.5 & 53.5 \\
\hline $\begin{array}{l}\text { major } \\
\text { surgery }\end{array}$ & 121 & 46.5 & 46.5 & 100.0 \\
\hline Total & 260 & 100.0 & 100.0 & \\
\hline
\end{tabular}

Adequacy of time allocation for patients in pre operative anaesthetist visit

$66.9 \%$ of patients felt that the time that the anaesthetists spent with them was limited. Only $16.5 \%$ felt that the time duration was adequate.

Time duration allocated to patients in the anaesthetist word visit

\begin{tabular}{|l|l|l|l|l|}
\hline & Frequency & $\%$ & $\begin{array}{l}\text { Valid } \\
\%\end{array}$ & Cumulative \% \\
\hline Inadequate & 43 & 16.5 & 16.5 & 16.5 \\
\hline $\begin{array}{l}\text { Some limited } \\
\text { time }\end{array}$ & 174 & 66.9 & 66.9 & 83.5 \\
\hline $\begin{array}{l}\text { Totally } \\
\text { adequate }\end{array}$ & 43 & 16.5 & 16.5 & 100.0 \\
\hline Total & 260 & 100.0 & 100.0 & \\
\hline
\end{tabular}

At the same time, if we consider the time duration the anaesthetist spent with the patients in relation to the type of surgery only $9.1 \%$ of patients who underwent major surgery were fully satisfied. $26.4 \%$ felt that the time duration was inadequate. Where as in minor surgery $23 \%$ felt that the time 
was adequate and only $7.9 \%$ felt that the time duration was inadequate.

Adequacy of explaining the anaesthetic procedure and its complications to the patient

91.5\% patients were satisfied with the explanation by the anaesthetist about the anaesthetic procedure and possible complications. Only $27.3 \%$ felt it to be adequate while $64.2 \%$ were not very convinced. $8.5 \%$ were not satisfied.

Explanation about anaesthetic procedure and possible complications

\begin{tabular}{|l|l|l|l|l|}
\hline & Frequency & $\%$ & Valid \% & Cumulative \% \\
\hline Not at all & 22 & 8.5 & 8.5 & 8.5 \\
\hline $\begin{array}{l}\text { Some } \\
\text { explanation } \\
\text { but not very } \\
\text { convinced }\end{array}$ & 167 & 64.2 & 64.2 & 72.7 \\
\hline $\begin{array}{l}\text { Adequate } \\
\text { explanation }\end{array}$ & 71 & 27.3 & 27.3 & 100.0 \\
\hline Total & 260 & 100.0 & 100.0 & \\
\hline
\end{tabular}

Next aspect of patient's view of anaesthetic pre operative visit was, whether they were given enough opportunity to express their view. $65.8 \%$ felt that some consideration was shown towards their expressed view. 29.2\% felt they had a good discussion and took part in decision making. 5\% felt that their views were not taken into consideration.

Opportunity to express their view and come to collective decisions

\begin{tabular}{|l|l|l|l|l|}
\hline & Frequency & $\%$ & $\begin{array}{l}\text { Valid } \\
\%\end{array}$ & Cumulative \% \\
\hline Not at all & 13 & 5.0 & 5.0 & 5.0 \\
\hline $\begin{array}{l}\text { Some } \\
\text { consideration }\end{array}$ & 171 & 65.8 & 65.8 & 70.8 \\
\hline $\begin{array}{l}\text { Good discussion } \\
\text { and decision } \\
\text { making } \\
\text { allowance }\end{array}$ & 76 & 29.2 & 29.2 & 100.0 \\
\hline Total & 260 & $\begin{array}{l}100 . \\
0\end{array}$ & 100.0 & \\
\hline
\end{tabular}

Relieving of Anxiety after pre op anaesthetic visit $66.5 \%$ felt that their anxiety was completely relieved following the pre operative anaesthetic visit. $26.9 \%$ did not feel any relief. Where as $6.5 \%$ said their anxiety worsened.
Relief of patients anxiety and acceptance of anaesthesia and surgery

\begin{tabular}{|l|l|l|l|l|}
\hline & Frequency & $\%$ & $\begin{array}{l}\text { Valid } \\
\%\end{array}$ & $\begin{array}{l}\text { Cumulative } \\
\%\end{array}$ \\
\hline Worsened & 17 & 6.5 & 6.5 & 6.5 \\
\hline Not changed & 70 & 26.9 & 26.9 & 33.5 \\
\hline $\begin{array}{l}\text { Improved } \\
\text { significantly }\end{array}$ & 173 & 66.5 & 66.5 & 100.0 \\
\hline Total & 260 & 100.0 & 100.0 & \\
\hline
\end{tabular}

Finally, in this audit we assessed the overall satisfaction of the patients, about the pre operative anaesthetist visit. To get the quantitative value, percentage satisfaction was considered. More than $90 \%$ of the patient population had varying levels of satisfaction. $50 \%$ of those who were satisfied had a satisfactory level below their expectations. Only $1 / 5$ of the patient population had very low levels of satisfaction.

On the other hand, if we consider the category of surgery with the level of satisfaction, patients who had major surgery showed a low level of satisfaction.

\section{Percentage satisfaction of anaesthetic visits}

\begin{tabular}{|l|l|l|l|l|}
\hline & Frequency & $\%$ & Valid \% & $\begin{array}{l}\text { Cumulative } \\
\%\end{array}$ \\
\hline $0-25 \%$ & 22 & 8.5 & 8.5 & 8.5 \\
\hline $25-50 \%$ & 73 & 28.1 & 28.1 & 36.5 \\
\hline $50-75 \%$ & 121 & 46.5 & 46.5 & 83.1 \\
\hline $75-100 \%$ & 44 & 16.9 & 16.9 & 100.0 \\
\hline Total & 260 & 100.0 & 100.0 & \\
\hline
\end{tabular}

\section{Conclusion}

According to this audit that we conducted in the population of surgical patients about their view on pre op anaesthetic visit, $90 \%$ of them accept that they benefited by the pre operative ward visit by the anaesthetist. Most of them were satisfied with the current conduct of the pre operative anaesthetic visit. But to make it a more worthy exercise, our anaesthetists need to spend more time with the patients, especially major surgical patients. In addition they should be explained the procedures in depth. When planning out the technique of anaesthesia, patient's views should also be considered carefully. 


\section{References}

1. Edward GM, Haes de JCJM, Oort FJ, Lemar LC, Hollman MW and PrekelB

Setting priorities for improving the preoperative assessment clinic; The patient and professional perspective Br jAnaesth 2008 100(3) 322-326

2. Shafer Audrey, Pamela M, Keith Fish, Gregg M , Seavello Julie, Kosek Peter

Pre operative anxiety and fear, A comparison of assessment by patints and anaesthesia and surgery resident. Anaesth Analgesia 1996:83 (1285-91)

3. Kalafta Jerome $M$ and Roizen Michael F:Current understanding of patients attitudes toward and preparation of anaesthesia-A Review Anaesth and Analgesia 1996 -83 (1314-21)

4. Pre operative assessment -The anaesthetists' rolePublished by the Association of Anaesthetists of Great Britain and Ireland.

5. Roizen M, Preoperative patient evaluation Canadian journal of Anaesthesia 1989 13(9) 363

$* * * * * * * * * * * * * * * * * * * * * * * * * * * * * * * * * * * * * * * * * * * * * * * * * * * * * * * * * * * * * * * * * * * * * *$

\section{THE COLLEGE OF ANAESTHESIOLOGISTS OF SRI LANKA}

\section{B S PERERA ORATION}

Applications are hereby called for the "B. S. Perera Oration", to be held on the $28^{\text {th }}$ January 2012 at the $28^{\text {th }}$ Annual Scientific Sessions of the college.

\section{Terms and Conditions for the Oration.}

1. Five copies of the entire oration should be sent before $31^{\text {st }}$ October 2011 to The Secretary, College of Anaesthesiologists of Sri Lanka and there should not be any substantial alteration in the text when the lecture is finally delivered.

2. The lectureship is open to all members of the College of Anaesthesiologists.

3. Five copies of a brief resume of the salient points of the paper should also be submitted indicating any contribution to further advances in knowledge of the subject.

4. The lecture should preferably not exceed 45 minutes.

5. A committee of five will be nominated by the council to scrutinize papers submitted and to select a suitable candidate. This committee of five shall award the lectureship.

6. The lecture should be related to anaesthesia and intensive care and should be based on the original work of the lecturer.

7. In the event of the committee being unable to select a lecturer from the applicants, they may invite a lecturer of international repute to deliver the lecture ship.

8. The honorium may be in the form of a gold medal.

9. Press should not be invited and photographs and accounts of the lecture should not be published in the Newspapers, without the permission of the College Council.

10. Copyright of the oration belongs to the College of Anaesthesiologists of Sri Lanka.

$* * * * * * * * * * * * * * * * * * * * * * * * * * * * * * * * * * * * * * * * * * * * * * * * * * * * * * * * * * * * * * * * * * * * * * *$ 